\title{
Poesia Corpo \& Cordas: Alternativas para Arte no Interior de Mato Grosso
}

Poetry Body \& Chords: Alternatives to Art in Mato Grosso's Hinterland

\section{Resumo}

Este artigo pretende apresentar o projeto de extensão Poesia Corpo \& Cordas, do curso de Letras da Universidade do Estado de Mato Grosso, campus de Tangará da Serra, em seu papel social no campus e na cidade. O projeto, atuante desde 2014, visou, inicialmente, a execução de repertório cultural alternativo ao que comumente é oferecido pelos meios de comunicação em massa, em festas e eventos locais, pretendendo atender tanto a um público que já buscava manifestações artísticas diferentes, quanto sensibilizar novos públicos em relação à diversidade cultural brasileira. Ao longo de quatro anos, outras atividades foram propostas conforme as demandas locais e habilidades de membros e colaboradores que foram surgindo. Inclui-se, como aspecto importante da evolução do trabalho, a aproximação com o universo da Educação Básica.

Palavras-chave: Diversidade cultural; Poesia; Música; Formação de repertório;

Everton Almeida Barbosa Álvaro Mendes de Melo everton@unemat.br Universidade o Estado de Mato Grosso (UNEMAT) 
Abstract

This article intends to present the extension project, titled Poesia Corpo \& Cordas, which is associated to the undergraduate course of Languages in the University of Mato Grosso State, Tangará da Serra campus, in its social role in the campus and in the city. The project, which has been in operation since 2014, initially aimed to implement a cultural repertoire that is alternative to what is commonly offered in mass media, at parties and local events, and aims to serve both an audience that already seeks different artistic manifestations and to sensitize new public to the Brazilian cultural diversity. Over the course of 4 years, other activities were proposed according to the local demands and skills of members and collaborators that were emerging. It is included, as an important aspect of the work's evolution, an approximation with the universe of Basic Education.

Keywords: Diversity; Poetry; Music; Formation; 


\section{INTRODUÇÃO}

Atualmente, tendo em vista a diversidade de meios virtuais pelos quais se pode experimentar a arte, em especial a música e o cinema, a percepção do valor e da predominância do consumo de determinados gêneros artísticos mostra-se sempre como tarefa de terreno instável, muito propensa, por um lado, às influências do gosto próprio, ou, por outro, às ressalvas da defesa da diversidade cultural. É, no entanto, notável, no contexto da cidade de Tangará da Serra, que se localiza a 240 Km da capital Cuiabá, no estado de Mato Grosso, o consumo massivo de gêneros artísticos que acompanha as estatísticas nacionais, dadas por instituições como o ECAD (Escritório Central de Arrecadação e Distribuição).

O ECAD é um órgão de iniciativa privada, representativo de associações de artistas nacionais e é responsável por arrecadar o valor referente aos direitos autorais dos artistas que possuem suas obras executadas em qualquer estabelecimento que vise lucro. Ele disponibiliza um relatório de arrecadação de direitos e execução de músicas desde 2013, a partir do qual é possível verificar quais artistas e músicas são os mais executados, em diversos setores, como casas de shows, festas, rádio, música ao vivo etc. Elencamos, portanto, o Ecad, por entender que ele seria uma das fontes mais confiáveis para indicar a prevalência ou não de um gênero musical, tendo em vista que sua informação é baseada em documentos comprobatórios de arrecadação.

Cruzando as indicações dos relatórios do Ecad com o contexto tangaraense, confirmam-se facilmente suas informações, a partir da observação da predominância de execução local de alguns gêneros musicais, bem como da frequência de aparição pública, pela TV ou internet, dos artistas vinculados a eles, ou ainda da frequência dos mesmos gêneros musicais e artistas em shows e festas locais. Todo esse preâmbulo tem o intuito apenas de indicar que, a considerarem-se os gêneros musicais e artistas mais tocados no Brasil, é possível perceber certa uniformidade, uma unidade característica no consumo de arte, quando tomado numa dimensão massiva. E por que isso ocorre? Por que, numa dimensão massiva, parece reinar a uniformidade ao invés da diversidade? A perspectiva com a qual este projeto trabaIha para dar resposta a esses questionamentos é a sugerida por Paula Sibila:

Tanto na internet como fora dela, uma característica da sociedade globalizada do século XXI é que a capacidade de criação costuma ser capturada pelos tentáculos do mercado, que atiçam como nunca essas forças vitais e, ao mesmo tempo, não cessam de transformá-las em mercadorias (SIBILA, 2008, p.10).

A captura da criatividade por parte do mercado, o estreito vínculo entre a produção artística e o rendimento que ela possibilita, marcado na presença das canções e artistas em comerciais, em telenovelas, filmes, cartazes e quaisquer outro meio pelo qual se pode fazer propaganda, acaba por ter, como efeito, o estabelecimento de certas fórmulas de sucesso, modelos de artistas, de gêneros musicais, de gestos etc., que atendem mais adequadamente ao perfil esperado pelo mercado. Mais do que emitir juízos de valor sobre a qualidade artística das produ- 
ções e pessoas envolvidas, o mais importante é notar que todo esse processo tem como efeito essencial a pouca expressão, numa dimensão massiva, do consumo da imensa diversidade cultural que o país oferece e que não se encaixa adequadamente aos padrões do mercado.

O desejo de oferecer a experiência da diversidade de produções artísticas existentes no país, tanto recentes, quanto mais antigas, é justamente o que moveu o projeto Poesia Corpo \& Cordas em seu início. Ele é uma iniciativa de professores do curso de Letras da Universidade do Estado de Mato Grosso, na cidade de Tangará da Serra, atuando, desde 2014, no mesmo intuito de ofertar à cidade uma opção cultural alternativa à que domina os meios de comunicação em massa.O grupo de trabalho é constituído por professores e alunos que possuem alguma habilidade artística. Foi pensado como atividade que complementasse, na perspectiva do trabalho extensionista, a formação dos acadêmicos do curso de Letras da instituição, dando-lhes repertório artístico alternativo, permitindo-lhes experimentar a diversidade cultural e a história de movimentos artísticos no Brasil com execuções ao vivo e não apenas por meio da internet, possibilitando-lhes, ainda, questionar e refletir sobre o que estava sendo apresentado. Por ocasião do contato com a Secretaria Municipal de Educação e Cultura do município, desde o início, as atividades se expandiram para a comunidade externa à universidade, em especial para professores da Educação Básica, que também se constituem como público-alvo importante, uma vez que conseguem, no cotidiano escolar, perceber os efeitos da falta de diversidade na oferta de arte na vida de jovens e crianças.

\section{METODOLOGIAS}

Em 2014, a proposta inicial foi a de realização de eventos aos sábados à tarde, direcionados aos alunos de Letras e professores da Educação Básica, com Concertos Didáticos, apresentados em associação com palestras sobre temas específicos, ministradas por docentes vinculados ao curso de Letras. A lista, com os primeiros temas das palestras e dos repertórios musicais, dá uma dimensão mais exata da proposição inicial:

\begin{tabular}{c|c} 
Mesa: Questões Identitárias & $\begin{array}{c}\text { Performance: A voz dos morros: } \\
\text { choro e samba }\end{array}$ \\
\hline Mesa: Migrações e alteridades & $\begin{array}{c}\text { Performance: A bossa nova: entre o } \\
\text { samba e o jazz }\end{array}$ \\
\hline Mesa: Autoritarismo e democracia & $\begin{array}{c}\text { Performance: Tropicalismo, festivais, } \\
\text { ditadura e vanguarda nos trópicos }\end{array}$ \\
\hline Mesa: Educação e Direitos Humanos & $\begin{array}{c}\text { Performance: Movimento Clube da } \\
\text { Esquina }\end{array}$ \\
\hline Mesa: Mídia, movimentos e expressões & Performance: Rock nos anos 80
\end{tabular}


Ao longo de cinco encontros, que se davam uma vez ao mês, durante 4 horas, a atividade, que foi chamada de Sábados com Ciência e Arte, atendeu cerca de 150 pessoas. Cada tarde se iniciava com uma mesa redonda e se concluía com um Concerto Didático, seguidos de um momento aberto para diálogo. No segundo semestre de 2014, o grupo deu continuidade à apresentação de repertórios temáticos, uma vez ao mês.

Em 2015, alguns membros do Poesia Corpo \& Cordas participavam em mais de um projeto de extensão na universidade, o que levou as equipes dos projetos a se decidirem pela oferta de ações de extensão conjuntas, que otimizassem o trabalho e os resultados. Dessa forma, passaram a ser oferecidos, também aos sábados à tarde, uma vez por mês, os Cafés Culturais, que se constituem de sessões de cinema, música, poesia e contação de histórias.A ação é feita em conjunto com o projeto Luz, Câmera, Forma(ação): Cinema alternativo em Tangará da Serra, do programa Novos Talentos. As performances lítero-musicais são feitas antes da exibição dos filmes e mantêm afinidade temática com estes. O projeto Poesia Corpo \& Cordas é responsável pela execução lítero-musical e o Cinema Alternativo pela exibição dos filmes, após os quais segue-se um diálogo sobre os temas abordados, que os membros dos projetos procuram evidenciar em todos os produtos artísticos apresentados. Os diálogos são provocados pelos alunos, com orientação dos professores membros, para que os demais participantes tenham um ponto a partir do qual possam comentar.

Esse formato de atividade permanece até hoje, com um número crescente de participantes, contando com a participação tanto de alunos de graduação, quanto de professores da Educação Básica e comunidade em geral. A escolha de filmes, músicas, poesias e histórias é orientada por reflexões feitas pelas equipes dos projetos em reuniões quinzenais de um grupo de estudos que reúne membros de todos os projetos envolvidos, nas quais textos teóricos são lidos e debatidos com professores e alunos participantes.

A partir do 2016, o projeto passou a oferecer uma oficina de vocalização de poemas, oferecida em parceria com a Secretaria de Educação e Cultura do município, para alunos, professores da educação básica e comunidade externa, que é mantida com frequência de uma vez por semestre. O currículo da oficina passa, basicamente, por noções do aparelho vocal, ritmo em música e poesia, escolha de repertório e noções de performance corporal e encenação. Acadêmicos que participaram dessas formações já se apresentaram diversas vezes nos eventos promovidos, tanto pelo projeto, quanto por professores em disciplinas do curso. Em 2017, outra atividade proposta foi a realização de intervalos culturais no corredor de salas do curso de Letras. Os intervalos são intervenções artísticas de 30 minutos, em que se apresentam músicas, declamação de poemas e contação de histórias. A atividade ainda é realizada, com frequência mensal, e tem a intenção, principalmente, de abrir espaço para a apresentação cultural de alunos. Ela se torna importante internamente ao curso de Letras, uma vez que muitos alunos não têm condições de 
participar da atividade aos sábados à tarde, por motivo de trabalho, ou por residirem fora de Tangará da Serra (o campus de Tangará recebe alunos de cidades que ficam até cerca de $90 \mathrm{~km}$ de distância).

\section{RESULTADOS}

A primeira proposta do projeto, os Sábados com Ciência e Arte, alcançou um público médio de 150 pessoas por dia de atividade. Nesses "Concertos Didáticos", apresentar canções e poemas e, ao mesmo tempo, dar informações sobre seu contexto histórico, autoria e cultura, abrindo espaço ao diálogo, caracterizou o trabalho como algo que vai além do simples entretenimento e propõe pensar-se sobre a arte e sua relação com a sociedade. A divulgação de artistas do passado, ou que estão fora do circuito midiático, proporcionou conhecimento de outras referências culturais, assim como a declamação de poemas trouxe uma experiência bem diferente do atual consumo de arte, que em geral se dá pela internet e TV e com base na perspectiva do simples entretenimento e da criação artística como mercadoria.

A realização de saraus e dos Cafés Culturais tornou-se uma opção a mais de lazer na cidade, mas que trabalha entretenimento e formação de forma conjunta, para que o sentido transformador da arte não seja perdido. Os temas escolhidos para filmes, músicas e poemas, suscitaram reflexões valiosas em que os participantes deram depoimentos pessoais sobre questões como depressão, reflexos sociais e culturais do individualismo, influência da internet no cotidiano, etc., mas também sobre temas como esperança, solidariedade e felicidade. Os resultados esperados de ambos os projetos envolvidos foram satisfatórios, nesses casos, pois sentiu-se, tanto pelo teor das perguntas quanto das manifestações dos espectadores, que houve sensibilização para problemas individuais e sociais que, muitas vezes, ou passam despercebidos ou são encarados naturalmente como aspectos da contemporaneidade, com os quais é necessário se conformar ou aos quais é necessário se ajustar de alguma forma, mesmo que causem sofrimento e tristeza. Os depoimentos tocaram questões comoa falta de sensibilidade com o sofrimento alheio, a falta de percepção de desigualdades sociais, o funcionamento perverso da ambição pelo lucro desmedido, os conflitos de identidade cultural e social, a disputa pelo poder etc. Em todos os casos, os participantes demonstraram um reconhecimento de como fatores como estes podem determinar o comportamento e as reações do indivíduo no contexto em que vive.

Na graduação, é possível ver o projeto Poesia Corpo \& Cordas como um estímulo à participação na arte entre alunos do curso de Letras, por meio dos intervalos culturais, ou saraus no corredor, como também são conhecidos. Muitos acadêmicos já se dispõem a participar das apresentações artísticas, declamando, cantando ou contando histórias, o que indica maior envolvimento, não apenas com os eventos, mas com a própria arte e a disposição para a performance, o que é muito importante para a formação do professor, no caso dos acadêmicos de Letras. A orientação musical do projeto já é conhecida e é maior 
entre o público a recepção à execução de músicas que estão fora do circuito da mídia massiva, tanto por serem antigas, quanto por serem de artistas com pouca circulação nesse meio.

Nas poucas apresentações ocorridas diretamente no espaço da escola de Educação Básica, a recepção ao repertório apresentado também foi satisfatório: mesmo com a predileção dos adolescentes pelo gênero musical funk ou pela música sertaneja, percebida em consultas feitas durante as apresentações, os alunos corresponderam ao repertório, alguns cantando, dançando ou mesmo procurando a equipe do projeto para diálogo após as apresentações. Foi possível ver que uma presença mais constante na escola pode suscitar o interesse, tanto pela arte que está fora da mídia de massa, quanto por se tornar participante em apresentações. A arte é uma necessidade do ser humano e isso fica bem claro quando, na experiência "ao vivo", o público se interessa pela aproximação com o artista. A experiência da arte via internet ou outros meios perde esse vínculo com a presença do artista, o que enfatiza ainda mais a perspectiva da arte como mercadoria, uma vez que ela é vista como produto acabado e não em constante estado de produção.

Como resultado do estímulo à reflexão teórica sobre a arte poética, em seu vínculo com a música e o corpo, o projeto, por meio de seus membros, já suscitou a produção de pelo menos três trabalhos de conclusão de curso de acadêmicos de Letras: um sobre as relações entre fotografia e poesia, que se debruçou sobre a comparação entre poemas da escritora Marta Cocco, poeta matogrossense, e Danny Bittencourt, fotógrafa gaúcha; um que realizou uma análise sobre a evolução das letras de músicas sertanejas, desde o chamado "sertanejo de raiz" ao "sertanejo universitário", destacando a visão de mundo implícita nas letras ao longo da história; e outro, com análise da poesia em letras de músicas, realizou a leitura e interpretação de canções da banda Engenheiros do Hawai, que, apesar do grande sucesso em sua época, compõe o que, para o projeto, considera-se como um momento histórico importante da música produzida no país. Esses trabalhos apresentam as mesmas perspectivas do projeto Poesia Corpo \& Cordas: produzir e divulgar material sobre produções artísticas alternativas ou que foram importantes historicamente; lançar um olhar diferente e questionador sobre a música consumida massivamente.

\section{DISCUSSÃO}

As escolhas de repertório têm sido pautadas principalmente pela ideia de reflexão e crítica de valores que empobrecem as relações humanas e reforçam a diferença social e a falta de sentido de coletividade e cooperação. Nas atividades oferecidas pelo projeto, são escolhidos repertórios que respondem de alguma forma a essa tendência ao empobrecimento humano e ao individualismo, com criatividade e criticidade. As reflexões que guiam as escolhas, como já se disse, são realizadas principalmente no grupo de estudos e reproduziremos aqui algumas reflexões contempladas no andamento do trabalho sobre os resultados da atuação do projeto. 
Poesia, corpo e música, que papel podem desempenhar em nossa comunidade? Para isso, nos balizaremos por algumas reflexões do filósofo italiano Giorgio Agamben presente em "Qué es un dispositivo" (2014) e pelo pensamento de Jean-Luc Nancy, em "Arquivida" (2014).Em primeiro lugar, Agamben, pensando a contemporaneidade, defende que nossa época histórica pode ser caracterizada pela massiva presença do que ele nomeia de dispositivos. Segundo o filósofo italiano, inúmeras redes cercam a vida do homem nos dias atuais, com o intuito de controlar, governar e administrar as subjetividades a uma finalidade específica: o consumo. Este status quo não restringe-se aos objetos físicos e materiais, mas está presente na cultura de um modo geral, implicando, também nas manifestações artísticas, por exemplo, que devem operar na rede e na lógica do dispositivo. Os projetos parceiros, Poesia Corpo \& Cordas e Cinema Alternativoem Tangará da Serra, vêm, ao longo dos últimos quatro anos, debatendo mensalmente junto com professores, acadêmicos do campus da Unemat e comunidade externa, o contexto de controle subjetivo de nossa época e a possibilidade de propor atividades culturais que sejam, desde suas elaborações, até suas execuções, possibilidades de linhas de fuga, ainda que momentâneas, do modelo hegemônico. Segundo Foucault:

[...] os processos de subjetivação indicam também possibilidades, (des) caminhos, fugas e subversão do próprio sujeito. Não se aponta aqui para a ideia de um sujeito livre, autônomo e soberano criador de suas condições de existência, mas para a condição de escapar dos poderes e saberes de um dispositivo para outro. Assim, podemos dizer que as linhas de subjetivação indicam também as linhas de fratura, de descontinuidade, de ruptura do próprio dispositivo [...]. (apud AMORIM MARCELLO, 2004, p. 209)

Neste sentido, ao propormos um repertório musical ou uma exibição fílmica, sem a lógica do consumo e lucro como gatilho, pensamos já sinalizar um descaminho em relação à dinâmica de nossos tempos. Fuga isolada, mas não por ser isolada perde seu caráter de subversão do dispositivo. Acreditamos que a conduta e o comportamento, podem ser de fato, o ponto de trinca e de rachadura, que comprometem e revelam a posição do dispositivo dominante com sua lógica, comportamentos e subjetividades.

Pergunta-se Agamben, "o que é um dispositivo?" (2014, p.07). Segundo ele, o termo passa a ser usado a finais dos anos setenta, com um sentido de governabilidade ou governo dos homens, (AGAMBEM, 2014). É um "conjunto heterogêneo que inclui qualquer coisa, tanto o linguístico como o não linguístico: discurso, instituições, edifícios, leis, medidas de política, proposições filosóficas, o dispositivo é a rede que se estabelece entre os elementos" (AGAMBEM, 2014, p.09). É a forma de poder de uma determinada época que está enlaçada ao 'conjunto heterogêneo' de elementos culturais. Isso, por si só, não pode ser negativado ou censurado com um olhar ideológico, que, operando no plano discursivo, retroalimenta o próprio dispositivo. O trabalho de revelar o dispositivo com a prática é bem mais árduo e, como sinaliza Foucault, solicita o corpo em ato. 
Para revelar o dispositivo é necessário saber que ele sempre atende a uma urgência, é uma forma que, em um determinado momento histórico, responde a uma urgência, e esta urgência está atrelada a uma rede de saber e poder (AGAMBEM, 2014). Qual é a urgência de nossos tempos? Com essas questões em mente, que incidem totalmente no comportamento e subjetividades sociais, os projetos supramencionados buscam interferir nos espaços coletivos da cidade de Tangará da Serra/MT. E sublinhamos que não é somente a questão de conteúdo (de filmes e músicas) que marca o ponto de fissura com a lógica de consumo, pelo contrário, é a presença do corpo, desprovido da urgência do dispositivo, que propõe uma alternativa de fuga.

Mas, uma pergunta é necessária: qual é o problema da lógica do dispositivo de consumo? Sabemos que ela se inscreve em uma relação de poder e saber, isto é, condiciona o saber e os produtos culturais circundantes. Ou seja, a ampla maioria de produtos culturais que chegam a circular estão condicionados pela lógica vigente. São dirigidos e possuem a sua natureza regulada por este a priori. Se o dispositivo, por sua força e presença, condiciona o saber, poderíamos concluir que almeja controlar o 'fazer', os comportamentos e as existências. O problema central é que o excesso de controle revela a falta de liberdade. Há, no âmago do dispositivo, uma natureza coercitiva, que induz, pressiona, compele alguém a fazer, ter ou ser alguma coisa. Quando a coerção, ainda que velada, é permanente, considera-se uma forma de escravidão, de obstáculo à liberdade humana. Outro problema da lógica do dispositivo de nossos dias é que, segundo o filósofo italiano, “'dispositivo' sempre implica um processo de subjetivação [...] produz, portanto, seu sujeito” (2003, p.16). Não existe a categoria "sujeito", em termos foucaultianos, fora da reflexão sobre o dispositivo, se é sujeito do dispositivo.

Portanto, somos dispostos em uma mesma direção e com uma mesma finalidade: "provavelmente, não seria errado definir a fase extrema do desenvolvimento do capitalismo que estamos vivendo como gigantesca acumulação e proliferação de dispositivos" (2003, p.19). Dentro desse contexto de extremo controle das subjetividades e comportamentos, que terminam sendo nocivos ao próprio homem, no sentido de sua liberdade de ser, - já que o nosso próprio 'ser' é apanhado pela rede - nocivos às relações humanas, - que tornam-se guiadas pela lógica do consumo prejudiciais ao planeta, - já que a lógica de extremo consumo é a mesma que está por trás, comprovadamente, do desmatamento das florestas, da escassez dos recursos naturais, da poluição do ar, água e solo, da produção descontrolada de lixo, da voragem de um homem sobre o outro - é possível fazer algo?

Agamben (2014), acompanhando a Foucault, sugere alguns caminhos de resposta que têm balizado a práxis de nossos projetos. A primeira delas não passa pela ideia de negação ou destruição, estratégia ingênua para o filósofo. Passaria mais por uma ideia de identificação da rede, de análise de seus efeitos para o próprio homem e de definir estratégias para escapar ao controle quase total que exerce. Portanto, afirma Giogio Agambem, "a estratégia que devemos adotar em nosso 
corpo a corpo com os dispositivos não pode ser simples. Porque se trata de liberar o que foi capturado e separado através dos dispositivos para restitui-lo a um possível uso comum" (AGAMBEM, 2014, p.21, tradução nossa).

Qual é o uso comum das manifestações artísticas musicais, por exemplo, seria uma pergunta norteadora. A cantiga de roda, a conversa sobre a letra de uma música, histórias sobre o compositor e seu contexto histórico, a integração com outros músicos locais fora da lógica do dispositivo, a música e a reflexão no pátio da escola e da universidade, têm sido algumas das respostas que estamos exercitando com o projeto Poesia Corpo e Cordas. Assim, pensamos poder estar profanando, termo do filósofo italiano, o dispositivo de consumo. Isso porque o dispositivo separa o homem do uso comum com alguma determinada atividade.A profanação tira para fora do dispositivo aquilo que foi capturado por ele. Profanar é devolver ao uso comum o que foi capturado.

O contemporâneo é o intempestivo, disse em outro momento o filósofo italiano. Em tempos como o nosso, o comportamento do contemporâneo pode ser a síntese do que buscamos apontar como estratégia diante do dispositivo, no sentido de produzir análises e diagnósticos de um determinado status quo e, assim, como bem sinalizou Jean Luc-Nancy (2014), propor estratégias de fissura do ciclo de produção, submissão, conformidade e oficialidade social e política. Colocar um contratempo a uma questão, propor um lugar não burocratizado (controlado), normalizado, uma parte da consciência que por momentos se descolonializa.

O filósofo francês traça um profundo diagnóstico de nossos tempos e vê na arte uma real possibilidade de ruptura do ciclo de produção e dominação. Seu diagnóstico sobre o quadro das subjetividades atuais é alarmante, fala de um presente de seres anões de espírito, conformistas, obedientes e infantis, altamente comandados e dirigidos (NANCY, 2014). Neste quadro, até certo ponto pessimista em relação ao homem, o filósofo propõe, como já dito, a arte como estratégia de ruptura ao dispositivo, mas não somente ela. Pensa no corpo como elemento de subversão. O corpo e a arte, o corpo presente, segundo ele, é capaz de tocar, agitar e fazer mexer, "toca agita e faz mexer. A partir do momento em que aproximo meu corpo do outro corpo [...] desloco o outro" (2014, p.16). Talvez aí resida o real alcance de nosso projeto de extensão, no fato de não somente buscarmos levar um conteúdo que entendemos pertinente por sua elaboração e significados, mas acima disso, pela presença humana, do corpo que desloca e agita a nossa situação atual de profundo solipsismo, de ausência, não só de poesia e cordas, mas de corpo.

\section{REFERÊNCIAS}

AMORIM, Marcello. O conceito de dispositivo em Foucault: mídia e produção agonística de sujeitos-maternos. Revista Educação \& Realidade, Porto Alegre, v.29(1), p.190-213, ja/jun 2004.

AGAMBEN, Giorgio. Qué es un dispositivo: seguido de El amigo y La Iglesia y el Reino. Buenos Aires: Adriana Hidalgo, 2014. 
NANCY, Jean-Luc. Arquivida: do sensciente e do sentido; tradução Marcela Vieira, Maria Paula Gurgel Ribeiro. I. Ed. São Paulo: iluminuras, 2014.

SIBILIA, Paula. O Show do eu: a intimidade como espetáculo. Rio de Janeiro: Nova Fronteira: 2008.

\section{ANEXOS}

Alguns dos filmes exibidos no Café Cultural (proposta conjunta entre projetos):

O nome da Rosa (Jean-Jacques Annaud, 1986)

O banheiro do Papa (César Charlone, 2007)

A chegada (Denis Villeneuve, 2016)

Biutiful (Alejandro Gonzáles Iñárritu, 2010)

Verônica decide Morrer(Emily Young, 2009)

O Preço do amanhã (Andrew Niccol, 2011)

O show de Truman, o show da vida (Peter Weir, 1998)

As sufragistas (Sarah Gravon, 2015)

Geração Roubada (Philip Noyce, 2002)

12 anos de escravidão (Steve McQueen, 2013)

O que é isso companheiro (Bruno Barreto, 1997)

A vila (M. Night Shyamalan, 2004)

Ensaio sobre a cegueira (Fernando Meirelles, 2008)

A onda (Dennis Gansel, 2008) 